\title{
The Development of Intelligent Transport System as Innovative Efforts to the Warning System Violation of Traffic Signs
}

\author{
Marson James Budiman \\ Department of Computer \\ Engineering, \\ Manado State Polytechnic
}

\author{
Stephy Walukow \\ Department of Computer \\ Engineering, \\ Manado State Polytechnic
}

\author{
Anthoinete P. Y. Waroh \\ Department of Computer \\ Engineering, \\ Manado State Polytechnic
}

\begin{abstract}
Violation of the signs are traffic signs that are installed in each road segment that occurs often due to the physical condition of signs, namely the position of traffic signs mounted not clearly observed by motorists because of the condition signs that have been damaged, there was a widening of the road which can eliminate the position of the signs as well as the bad behavior of motorists who deliberately violate the rules so that this condition resulted in the occurrence of traffic congestion and accidents. Based on these events, the need for the system the giver of the cue of traffic signs for road users especially motorists that can provide information quickly when a rider pass through the roads which are the object of the placement of traffic signs. The test results showed that the system created can detect the position of the traffic signs detected by the GPS by comparing the set point position coordinates of the traffic signs in each object the placement of signs. As for the sample types of traffic signs which become the object of research is the Traffic light intersection of three and four, prohibited parking, prohibited to turn left and right, with the distance of the response system $25 \mathrm{~m}-30 \mathrm{~m}$ to the traffic signs, when the detected object traffic signs, the system will give an indication of the form of a voice according to the character and type of signs that are detected. Testing the response of the system was conducted by testing three provider service provider access GPS signals, respectively, for the Tri, Telkomsel, and Indosat, the average access time of 11.3 seconds. This application is expected to facilitate the motorists to find out the presence of signs-traffic signs accompanied by features media player (voice), in order to increase the quality of the management of traffic.
\end{abstract}

\section{Keywords}

Traffic signs, Management Traffic, GPS Traker

\section{INTRODUCTION}

Traffic signs is one of the road equipment which can be either symbol, letter, number, phrase or combination of these that serves as a warning, ban, orders or instructions for users of the road. As a road user, whether a rider car, motorcycle, or pedestrian should comply with any traffic signs on the road to common security. Violation of traffic signs by the user of the motor vehicle which often occur in each road section caused by the behavior of the road users are not obedient to the traffic rules, but it is also the condition of traffic signs that have been damaged so it is not clearly observed by road users [6]

With the advancement of technology can answer the problem is not terpantaunya position signs laulintas or violation of traffic signs by the users of the road, i.e. with the presence of ternologi determining location such as GPS are growing rapidly with the level of accuracy that the more meticulous, diverse variety, and getting cheaper. The position can be known if the carrying device named a GPS receiver which receives signals from the GPS satellites. On the article will be designed the design of the system the giver of the cue of traffic signs by tracking using GPS technology by utilizing Google Maps through GSM communication.

The application will be designed is preferred for road users who use four-wheeled vehicles that can comfortably drive any roads without having to be distracted by the atmosphere to a standstill. Through this application expected can assist the relevant agencies, namely the regional police of north Sulawesi to provide a good service to the community of road users

\section{METHODOLOGY}

\subsection{Research Design}

At this stage will be carried out to identify the existing problems, in order to be able to anticipate all of the problems associated with entry into the new system. The problems that are identified is a Way to monitor violations of traffic signs.

Designing an application is made to determine the components of the modules forming the application to be designed and the process contained therein using the Unified Modeling Language (UML) which will make the use case diagram, flowchart and of the process of analysis and design of object-oriented. This application runs under the operating system Android. [14]

\subsubsection{Use Case Diagram}

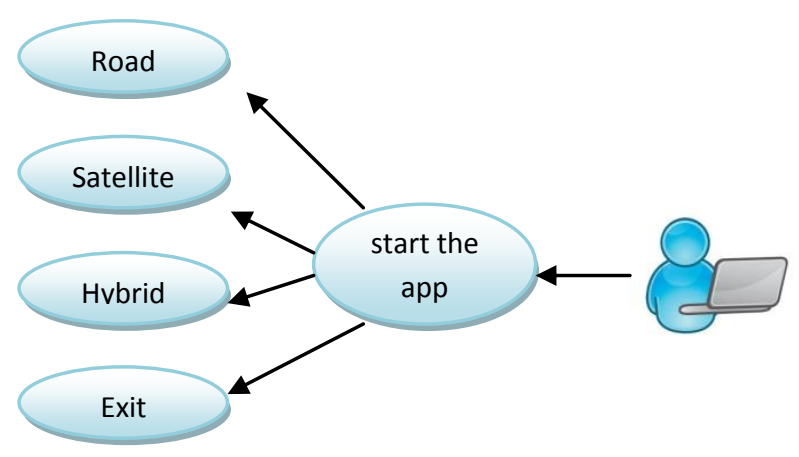

Fig. 1 Use Case Diagram

Use case diagram of fig. 1 describe about the user that uses the application. The User here is a user who want to do simulation test calculation. There are several activities that can be done by the user in this application, among others : If the user accesses the application icon simulation of the detection system, then the system will display the initial view 
of the application and the user should access the button button start application to be able to use the app, If the user access the Path menu, then the system will display the position coordinates of the user, If the user selects the menu Channels, then the system will display a Satellite Photo display, If the user selects a menu Hybrid then the system will display a Road Map, a satellite photo with the appearance of the street name and the name of the city, If the user selects Exit, then there will be features alert dialog to confirm if user wants to exit the application after the selection is selected the system will respond to and get out of the app

\subsubsection{Flow Chart Sistem}

Flow chart of the system shown in Fig. 2.

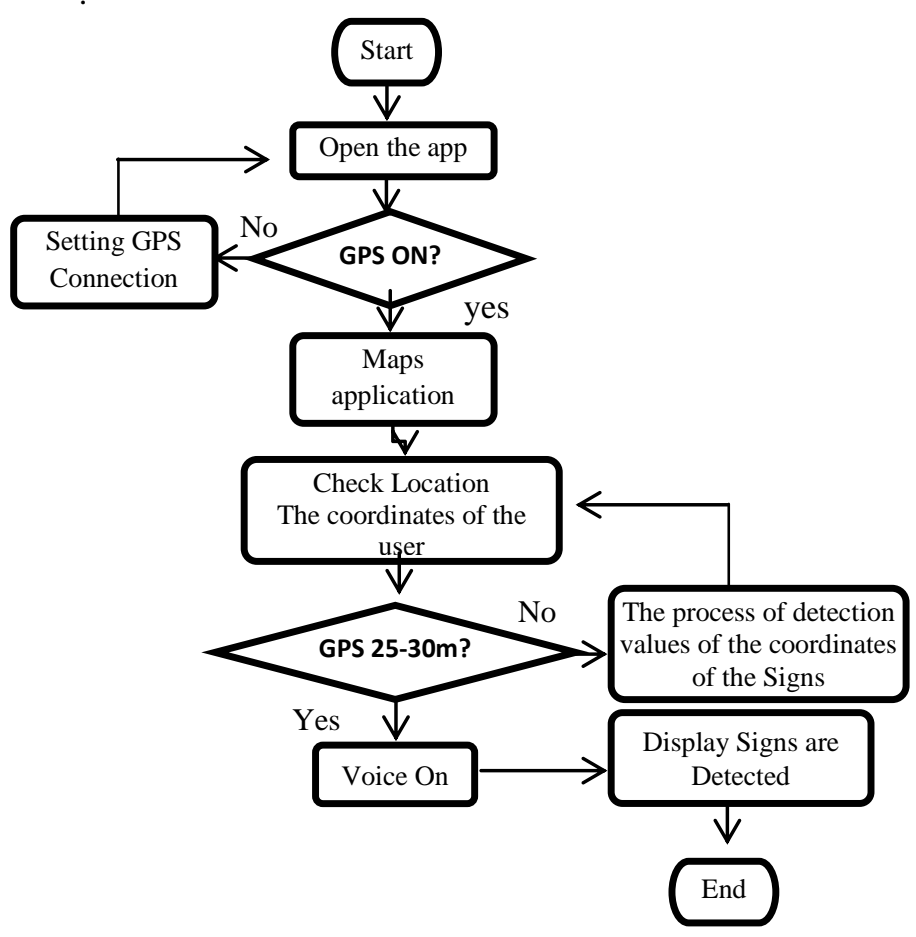

Fig. 2 Flow Chart of the System

Description of the system algorithm as the following: The initial stage the system will read the on state to activate the whole system.with open system applications, Once the system is active, the system will access the GPS signal, Next the system will read the menu of the app when GPS is active, The next stage, read the GPS data of the user and then compare it with the value of the setpoint. The coordinates of the signs, If the data signal of the GPS user in the ranges of 25-30 meters, the system will indicate a detected object point signs, If the gps data in accordance with the set point then are sismtem will activate the voice types of signs are detected., If the GPS data user is not the same with the set_point then the system will again read the coordinates of the signs continuously throughout the GPS user active

\subsection{The planning stage}

At this stage of system design. The research plan as follows: starting from a survey of the field up with a system of detection of traffic signs in accordance with the research objectives that have been set. On this system would be made information system map showing the location of traffic signs to the detection of violations of traffic signs. With the design of the system such as in fig. 3 .

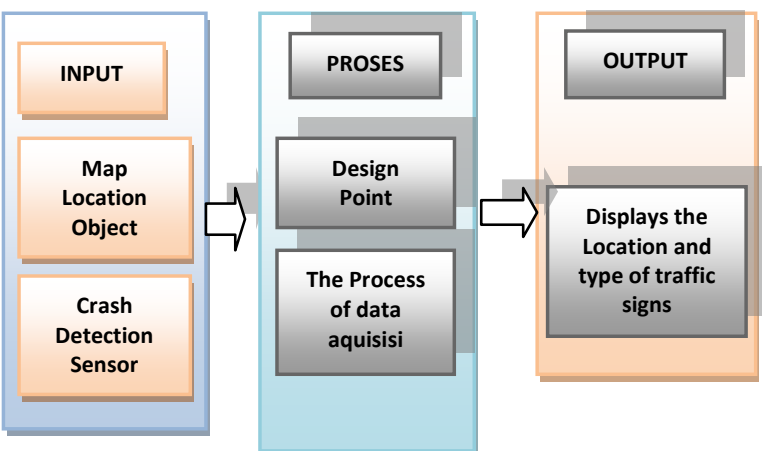

Fig. 3 system design diagram

\subsection{The implementation stage}

At this stage of the development of the system architecture based on the results of diagnostic analysis of system requirements, as well as testing the system by measuring the speed of user access. The system will inform the location and condition of violation of the traffic signs displayed at the coordinates of the map location.

\section{RESULTS AND DISCUSSION}

In the process of interface systems there are several options that support business process system. Briefly this process are as follows: Process design point coordinates (Admin), Process monitoring (User / Client), Process report (Admin) The Admin will handle the design process, and the Report, while the User or Client will relate to process information systems As the stages are done in building applications, namely:

\subsection{The design process coordinate point}

3.2 Point koordinati to display a map and route that aims to find out if there are still errors in the making or still need additional and correction on every Menu, as can be seen as follows:

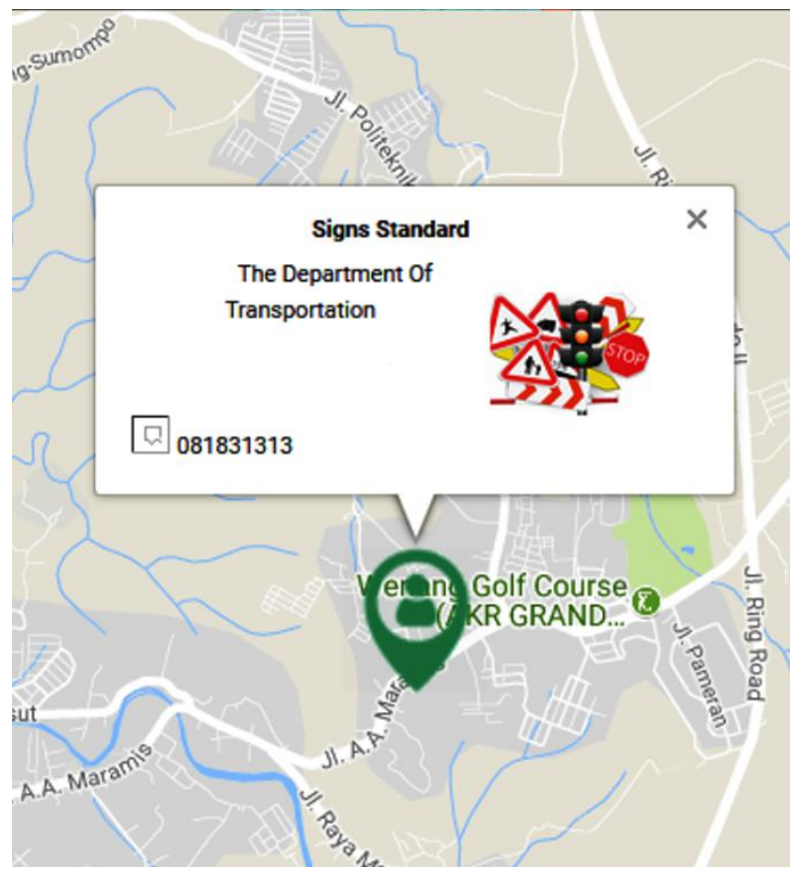

Fig. 4 The App detector of traffic signs

Fig.4 displays the map coordinates of the location of traffic signs, used to display a map of the location of the study area in units of Latitude and Longitude coordinates. 


\subsection{Testing the Response of the System GPS Signal}

On the implementation of the testing system response in the test using the scenario process of the system starting from the detection of the GPS signal with active status with the coordinates of latitude : 1.50123521 , longitude : 124.84204848 on the road sindulang 1 icon blue prove active GPS in accordance with the position coordinates of the user on the testing of three providers:

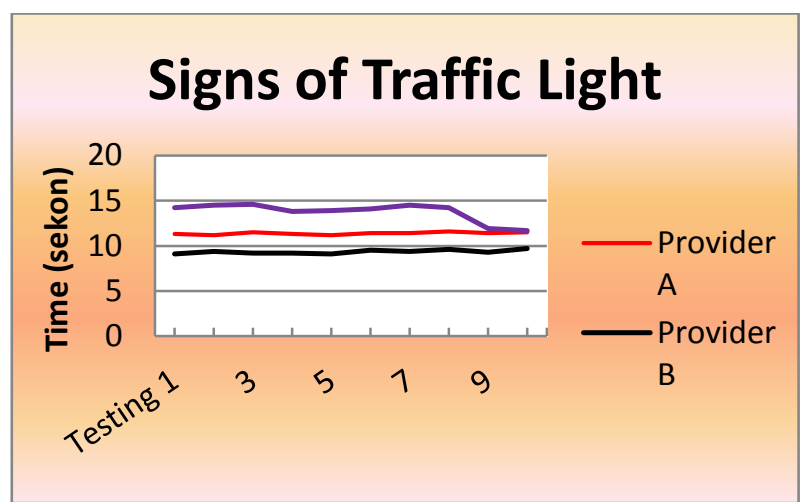

Fig.5 Access Object 1 traffic Signs Traffic Light

In fig.5. The results of Testing the response of the system on the object 1 is to perform testing provider A,B and $\mathrm{C}$ it can be concluded that the response time is the fastest to turn on the active gps is provider B with the average response time of 9.1 seconds with a response of the voice on

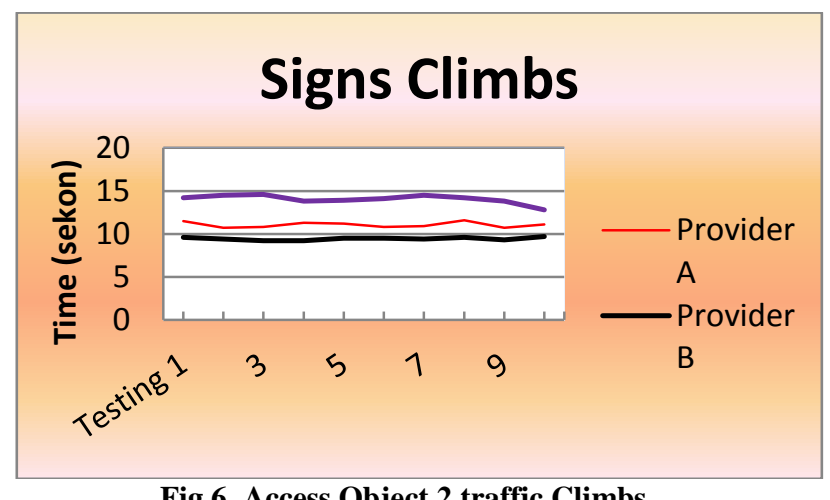

Fig.6 Access Object 2 traffic Climbs

In fig. 6. The results of Testing the response of the system on object into two is to do the testing provider A,B and C it can be concluded that the response time is the fastest to turn on active gps is a provider of B with an average response time of 9.4 seconds with the results of the voice response system

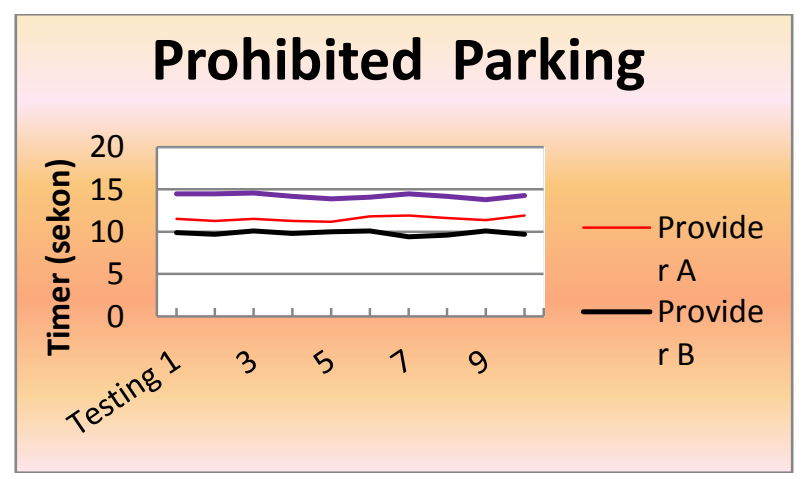

Fig.7 Access Object 3 traffic Signs Prohibited Parking
In fig.7. The results of Testing the response of the system on the object to three is to do the testing provider A,B and C it can be concluded that the response time is the fastest to turn on active gps is a provider of B with an average response time of 9.9 seconds with the results of the voice response system

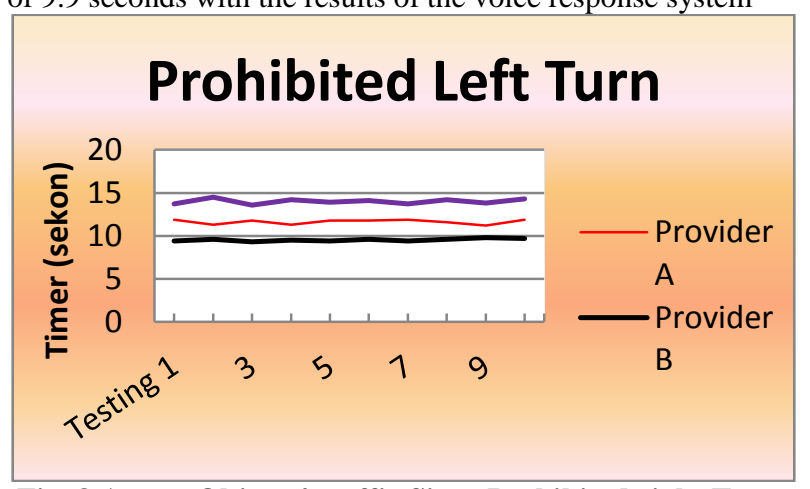

Fig. 8 Access Object 4 traffic Signs Prohibited right Turn

In fig.8. The results of Testing the response of the system on the object 4 is to do with provider A,B and $\mathrm{C}$ it can be concluded that the response time is the fastest to turn on active gps is a provider of $\mathrm{B}$ with an average response time of 9.6 seconds with the results of the voice response system

\subsection{Testing voice Response}

Table 1. Testing the response voice detection system, traffic signs

\begin{tabular}{|c|c|c|c|c|}
\hline No & Coordinate & $\begin{array}{l}\text { Types of Signs- } \\
\text { traffic signs }\end{array}$ & $\begin{array}{l}\text { The distance } \\
\text { to the } \\
\text { coordinates of } \\
\text { the traffic } \\
\text { signs }\end{array}$ & $\begin{array}{c}\text { Respon } \\
\text { voice }\end{array}$ \\
\hline 1 & $\begin{array}{c}1.490659, \\
124.839181\end{array}$ & Traffic Light & $\langle=30 \mathrm{~m}>=25$ & On \\
\hline 2 & $\begin{array}{l}\text { 1.49338711, } \\
124.8712912\end{array}$ & Traffic Light & $\langle=30 \mathrm{~m}\rangle=25$ & On \\
\hline 3 & $\begin{array}{c}1.50061624, \\
124.89123154\end{array}$ & Traffic Light & $\langle=30 \mathrm{~m}>=25$ & On \\
\hline 4 & $\begin{array}{c}1.4940721, \\
124.88214505\end{array}$ & Traffic Light & $\langle=30 \mathrm{~m}>=25$ & On \\
\hline 5 & $\begin{array}{c}1.4964506, \\
124.87745449\end{array}$ & Traffic Light & $\langle=30 \mathrm{~m}>=25$ & On \\
\hline 6 & $\begin{array}{c}1.536177, \\
124.83865073\end{array}$ & Traffic Light & $\langle=30 \mathrm{~m}>=25$ & On \\
\hline 7 & $\begin{array}{l}1.48994913, \\
124.8386679\end{array}$ & Traffic Light & $\langle=30 \mathrm{~m}>=25$ & On \\
\hline 8 & $\begin{array}{c}1.518071, \\
124.887290\end{array}$ & Traffic Light & $\langle=30 \mathrm{~m}>=25$ & On \\
\hline 9 & $\begin{array}{c}1.491029, \\
124.838260\end{array}$ & Traffic Light & $\langle=30 \mathrm{~m}>=25$ & On \\
\hline 10 & $\begin{array}{c}1.50073788, \\
124.89165705\end{array}$ & traffic Climbs & $\langle=30 \mathrm{~m}\rangle=25$ & On \\
\hline 11 & $\begin{array}{c}1.492098, \\
124.838604\end{array}$ & $\begin{array}{c}\text { Signs } \\
\text { Prohibited } \\
\text { Parking }\end{array}$ & $<=30 \mathrm{~m}>=25$ & On \\
\hline 12 & $\begin{array}{c}1.505280, \\
124.842987\end{array}$ & $\begin{array}{c}\text { forbidden to } \\
\text { turn right }\end{array}$ & $<=30 \mathrm{~m}>=25$ & On \\
\hline 13 & $\begin{array}{c}1.499781, \\
124.845568\end{array}$ & $\begin{array}{l}\text { prohibited left } \\
\text { turn }\end{array}$ & $\langle=30 \mathrm{~m}>=25$ & On \\
\hline
\end{tabular}


In table 1. Testing the response of the sound system on some of the coordinates are already in the input with the type of traffic signs that have been determined and the distance to the coordinates of the traffic signs is $<=30 \mathrm{~m}$ or $>=25 \mathrm{~m}$ and the results of the response of active voice.

\section{CONCLUSIONS}

Made system can detect the position of the traffic signs detected by the GPS by comparing the set point position coordinates of the traffic signs in each object the placement of signs. As for the sample types of traffic signs which become the object of research is the Traffic light intersection of three and four, prohibited parker, prohibited to turn left and right, with the distance of the response system $25 m-30 m$ to the traffic signs, when detected objects signs and ave the system will give an indication of the form of a voice according to the character and type of signs that are detected. Testing the response of the system was conducted by testing three provider service provider access GPS signals, respectively, for the Tri, Telkomsel, and Indosat, the average access time of 11.3 seconds. This application is expected to facilitate the motorists to find out the presence of signs-traffic signs accompanied by features media player (voice), in order to increase the quality of the management of traffic.

\section{ACKNOWLEDGMENTS}

Thanks to the Ministry of Research and Technology of Technology and Higher Education, which has funded this research with competitive grants program in 2017, so as to do research and work well.

\section{REFERENCES}

[1] Abu Bakr Iskandar.DKK. 1995. Towards Traffic and Road Transport are tongue, Jakarta. Directorate General of Land Transportation.

[2] Aries Setijadi, Road Traffic Congestion Study Kaligawe City Semarang, Semarang Diponigoro University thesis

[3] Afrias Sarotama, Mohammad M. Sarinato, Juniar Ganis, Development of Interactive Electronic Map, proceedings KOMMIT 2002

[4] Bob D. Sinulingga, Urban Development and Regional Local Review,Publisher Pustaka Sinar Harapan, 1999.
[5] D.Setijowarno \& RB Frazila, Introduction to Transportation Systems, Publisher Catholic University of Semarang Soegijapranata 2001

[6] Eko Budihardjo, the City Spatial Urban, Publisher Alumni, 1997

[7] HA Abbas Salim, Transportation Management, Publisher PT. King Grafindo Persada Jakarta, 1993. [8] Hadihardja, Joetata. DKK. 1997.Sistem Transportation. Jakarta. Publisher Guna Darma.

[8] Sugiyono, "Understanding Qualitative Research", Bandung, Alfabeta 2012.

[9] W. Gulo, Research Methodology, Grasindo Publishers, 2002.

[10] Ofyar Z. Tamin, planning and transport modeling, Publisher ITB Bandung, 2000.

[11] James Marson Budiman, Zahir Zahinuddin, Amil Ahman Ilham, Monitoring and Control Systems Urban traffic Jurnal Hasanuddin University, 2012.

[12] Andy AM Malik, identification of traffic congestion in the city center Paal2 and Manado. Sam Ratulangi University in Manado, 2011.

[13] Warpani.S, plainly traffic management and road transportation, ITB, Bandung, 2002.

[14] Mokhamat Ansori, Mohammad Kanzunnudin, Application Traffic Management in the field of transportation, STIEPARI, Semarang, 2000.

[15] Budiman, Marson James, Stephy Walukow, and Herry Makapedua. "Development of Intelligent Transport System for Detection System Location Traffic Accidents." Development 151.11 (2016).

[16] Budiman, Marson James, Stephy Walukow, and Indri Patolenganeng. "Pengembangan Sistem Pemberi Isyarat Jenis Rambu Lalu Lintas Bagi Pengguna kendaraan Bermotor Berbasis GPS." Prosiding Industrial Research Workshop and National Seminar. Vol. 8. No. 3. 2017 